\title{
Experimenting intermediate lived spaces in residential subdivisions: Action, interaction and storytelling
}

\author{
Teresa Palmieri $^{1}$ and Marion Serre ${ }^{2}$ \\ ${ }^{1} \mathrm{PhD}$ student, Faculteit Architectuur \& Kunst - Faculty of Architecture \& Arts, Hasselt \\ University, Belgium \\ ${ }^{2}$ Architect, $\mathrm{PhD}$ in architecture, Project[s] research laboratory - ENSA-Marseille, France
}

\begin{abstract}
Suburbanization and more precisely the development of residential subdivisions in Europe are at the core of many current debates. Over the years, they have been strongly criticized for the waste of land, increased infrastructure and network costs, car-dependency and the lack of urbanity. In this context, two processes are politically-driven in Europe: the densification of residential areas and the revitalization of the city centers. These political guidelines interrogate the transformation - and possible deterioration - of living environments and ambiances of residential subdivisions. Indeed, beyond the negative perspectives, other investigations have revealed the potentials of residential subdivisions from different points of view: ecology, social, architectural and urban. In order to contribute to these studies, this paper proposes to investigate the intermediate lived spaces in the specific context of residential subdivisions.
\end{abstract}

\section{Introduction}

Suburbanization and more precisely the increasing development of residential subdivisions in Europe are at the core of many current debates, on broad scientific and political levels. Over the years, they have been strongly criticized for the waste of land, increased infrastructure and network costs, the intensification of motorized transportation, individualism and the lack of urbanity ([1], [2]). In this context, two processes are politicallydriven in Europe: the densification of residential areas ([3], [4]) and the revitalization of the city centers ${ }^{1}$. These political guidelines interrogate the transformation - and possible deterioration or decrease - of living environments and ambiances of residential subdivisions. Indeed, beyond the negative perspectives previously mentioned, other investigations have revealed the potentials of residential subdivisions from different points of view: ecological ([5]), social ([6], [7]), architectural and urban ([8]).

1 For example: Seminar "Urban degrowth and land declines" ("décroissance urbaine et déprise foncière"), PACT Laboratory, Grenoble, April 2018. 
In order to contribute to these studies, this paper proposes to investigate the intermediate lived spaces in the specific context of residential subdivisions. What are their forms, perceptions, social relations? What kind of interaction between public, private, individual and collective dimension do they reveal? Furthermore, what kind of interaction between institutional and residential strategies do they enlighten? What capabilities do they unveil? Could they trigger projects of transformation to emerge contextually enhancing citizen capabilities and help to develop more sustainable futures for these living environments ${ }^{2}$ ?

To provide answers to these questions, we will first define the concept of intermediate lived spaces by relying on founding theories and show how it enlightens living spaces and ambiances in residential subdivisions. Secondly, we will give some examples of existing intermediate lived spaces, describing 1) how they have emerged (which action?), 2) what kind of socio-spatial situation they create (what interaction?), and 3) what narratives and meanings they produce (which storytelling?). Hence, through experimenting intermediate lived spaces in residential subdivisions, we will mainly discuss the relation between two attractors of the concept of "ambiance": on the one hand, architecture and the city and on the other hand, uses and perception.

\section{Intermediate lived spaces: between private, public, collective and individual dimensions}

Over the years, studies in the field of lived spaces have explored various forms of "inbetween", investing different concepts and notions, such as intermediate spaces ([9], [10]), third spaces ([11]), interval spaces ([12]), urban interstices ([13]), common spaces ([14]). Each of these concepts has been used to focus observations and reflections on certain characteristics. For example, third spaces defined by Soja (inspired by Lefèbvre and Foucault) are mobilized to reveal the interactions between "real and physical environment" (First space) and "imagined representation" (Second space). Another example, common spaces are defined by Stavrides as those that, by escaping the control of prevailing authorities and by distinguishing themselves from public and private spaces, renegotiate spatial rules and roles toward the creation of new forms of spatial sharing and common life. Based on these various definitions: seeing residential subdivisions through the lenses of intermediate lived space could help us relate them to future-making processes ([15]) and the development of more sustainable alternatives for these environments.

In design and ethnography research fields, Pink advances the definition of homes as ongoing projects that are being made and remade continuously by inhabitants materially and imaginatively: the home "is never completely realised materially, but instead exists partially in one's own imagination as a series of constantly developing dreams or plans" ([16]). Pink proposes the home as a possible entry point for future-making processes and design interventions that aim at developing more sustainable everyday living. However, as she explains, when researchers and practitioners engage with domestic environments as sites for change, they cannot avoid considering how people, "as everyday designers", are constantly transforming their homes through their material and imaginative engagement with everyday

\footnotetext{
${ }^{2}$ These questions are explored within the framework of the CAPA.CITY research program (JPI Europe 2017-2020), which questions the capabilities that need to be mobilized and associated in order to transform existing residential subdivisions. The originality of this approach lies in the interrogation of creating negotiation spaces between individual, collective and common interests, so that collective capabilities could be built between the different actors (inhabitants, professionals, institutions) implicated in the transformation of residential subdivisions.
} 
environments. Looking together at perceived and imagined space can facilitate to understand this relation between the ways people live and imagine to live in their homes, and how it might already shape inhabitants' everyday lives and the materiality of their environments.

Like the home in Pink's definition, intermediate lived spaces of residential subdivisions can be attended to as 'projects'. By overcoming the strict separation between private and public spaces and individual and collective uses, which most commonly defines suburban monofunctional neighbourhoods, these spaces are the result of ongoing negotiation and imagination that can unveil possibilities for questioning and envisioning future alternatives for residential subdivisions in the present together with residents. In this perspective, we propose to define and identify them in residential subdivisions through the following model (Figure 1), in which:

- Public and private dimensions are related on the ownership status of the space: who does it belong to?

- Individual and collective dimensions are related on the uses and perception of the space: who can use it, who does actually use it, why and how?

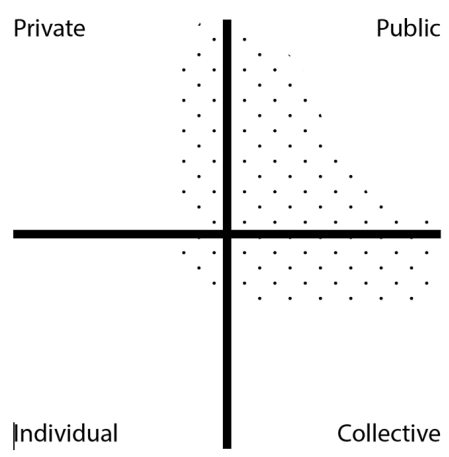

Fig. 1. Intermediate lived spaces analysis model (c) Marion Serre and Teresa Palmieri

This theoretical framework, put into perspective with the case studies, notably illustrates the negotiation between public and private spaces and between individual and collective uses, creating specific lived spaces and ambiances. Furthermore, it will reveal appropriation processes, strategies and tactics ${ }^{3}$ developed by the inhabitants to adapt their living environment and ambiances to their needs.

\section{Intermediate lived space as day-to-day city stages}

The paper presents two case studies as part of the European Research project CAPA.CITY, one residential subdivision in Belgium (Lanaken, figure 2) and one in France (Aix-enProvence, figure 3). They have been chosen as being typical suburban neighbourhoods, presenting common local challenges such as the lack of services and public spaces, the ageing of the population, space underuse, and the lack of connection with its surroundings. The

\footnotetext{
${ }^{3}$ A strategy refers to a set of coordinated actions, clever operations and maneuvers to achieve a specific goal. While a tactic refers to several actions carried out one by one, caught depending on opportunities (de Certeau, 1980).
} 
residents were interviewed in their homes and were facilitated to explain and visualise how they live individually and collectively in the neighbourhood by using paper models of an average house of the area and/or maps.
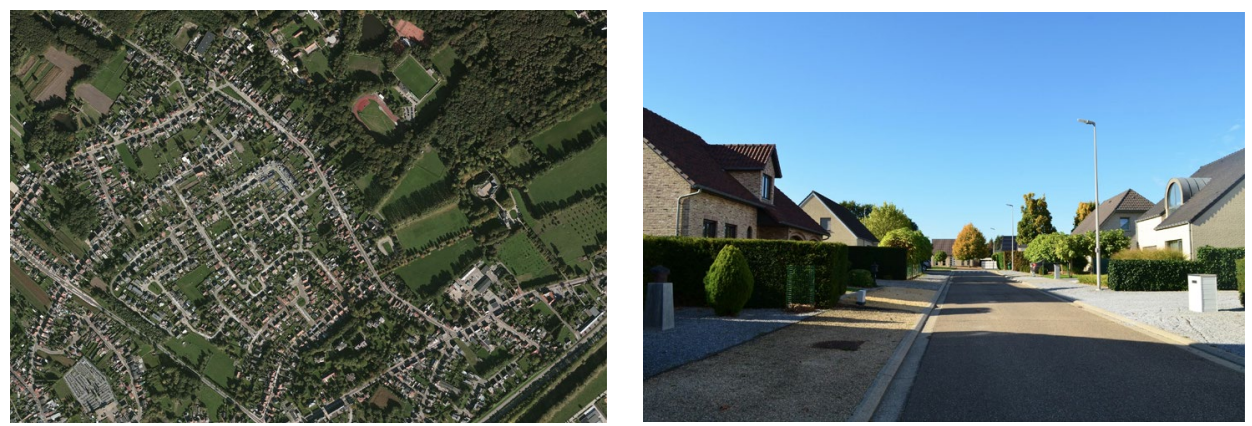

Fig. 2. Residential subdivision in Lanaken

Lanaken is a small town in Flanders on the border with the Netherlands. The residential subdivision examined was developed by the municipality in the nineties as a reaction to the local trend that was seeing young people leaving the area. New plots were offered for affordable prices for young local citizens to buy and develop their own housing project. If Lanaken experienced a phase of population growth in the half of the last century with the development of housing projects, today the situation has changed and Lanaken has recently been confronted with a real-estate crisis due to the inability of selling large and old properties present on its territory and space underuse is increasing. To face local socio-economic and demographic trends, such as the aging of the population, lack of local economy, decreasing of household size, the municipality started questioning the possibilities to transform residential subdivisions into more diverse, green and liveable environments.
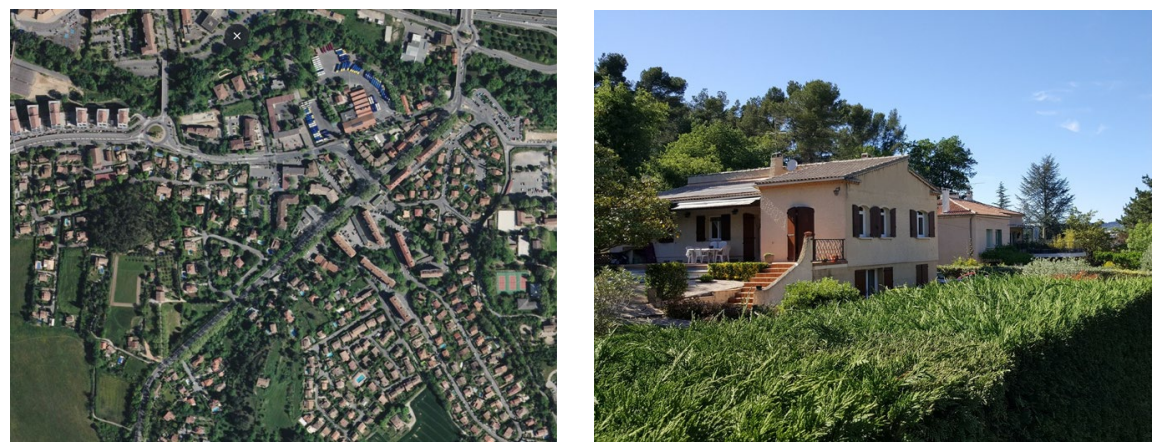

Fig. 3. Residential subdivision in Aix-en-Provence

In Aix-en-Provence, the residential subdivision was built in the 1960s. Recently, the municipal plan has been revised in order to increase the density of the outskirts already built. In this context, the district will have to support many urban transformations in a few years, such as (1) densification of residential subdivision villages such as La Clairnande, (2) urbanization of selected areas, especially old farmland, (3) creation of a new university with student accommodation, (4) creation of new infrastructures such as new streets and missing sideways. The openness of the rights to build has attracted several real estate developers to the residential subdivision. One of the residents tried to sell his house in 2017. As a consequence, the homeowners have filed a lawsuit against the city arguing for the 
inappropriateness of the allowed densification in the municipal plan claiming that their internal regulations could not allow such transformations. This example, in which, private interests conflicts with the public one, is very characteristic in France and is often used to block densification processes.

Both cases are currently facing future transformations, due to the upgrading of regulations and new planning strategies. In these contexts, the field surveys reveal that the inhabitants are not passive and that their actions on their own environment interrogate several characteristic stereotypes of residential subdivisions, such as homogeneity, individualism, car-dependency. Hence, by their differences and their similarities, these two cases can speak for European residential subdivisions, showing inhabitants' initiatives to adapt their environment. Among them, about fifteen intermediate lived spaces, created by the inhabitants, have been identified through the field surveys and classified in three categories:

1. Porous limits: private spaces transformed by collective and individual uses

2. Transition spaces: public spaces appropriated by collective uses

3. Street interaction: public and private interfaces used by individuals

These fifteen situations show a wide range of interactions between private, public, collective, individual dimensions and the capabilities of the inhabitants to modify their environments. To illustrate this, we present two examples for each of the mentioned categories.

\subsection{Porous limits}

We defined porous limits as the private spaces that are transformed by inhabitants together or individually to accommodate collective uses, confront individual and collective needs and that promote practices of sharing between the inhabitants of residential subdivision.

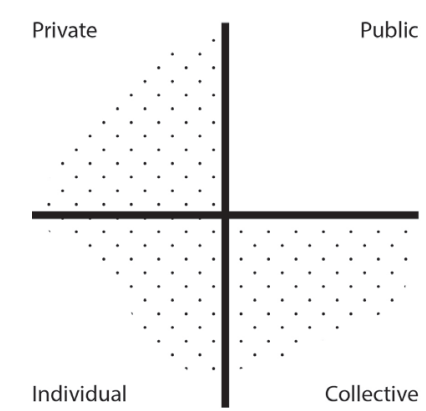

Fig. 4. Intermediate lived spaces analysis model: porous limit (c) Marion Serre and Teresa Palmieri 


\subsubsection{Sharing private gardens in Aix-en-Provence:}

Fig. 5. Sharing private garden in Aix-en-Provence ๑ Safa Ben Kheder

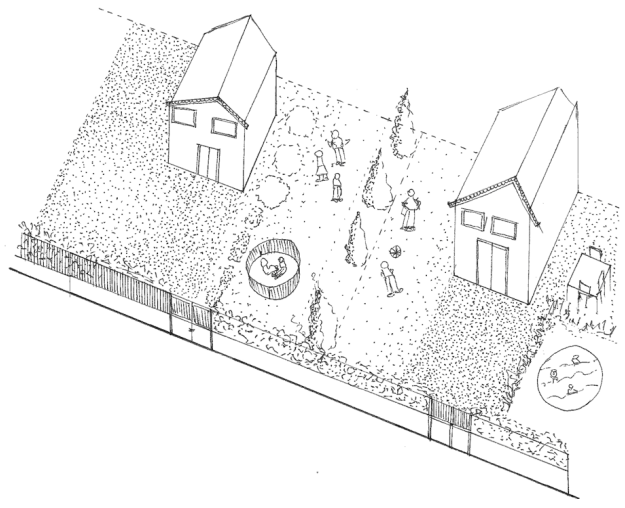

Action: Two families decided to remove the fence between their gardens. They kept a natural delimitation with existing trees and shrubs. This action reveals the capacity of the inhabitants to divert dwelling models (unlike Nordic or US models, fences are an integral part of the French model of suburban housing) and legal rules. Indeed, the internal regulations of their residential subdivisions have specific rules for fences:

"The fences separate the lots by a wall of one meter maximum, surmounted by an iron grating or any other device submitted for approval to the Departmental Service of Urbanism."

Interaction: Due to this transformation, these two families share a swimming pool, a trampoline, but also guest rooms, kitchen and gardening tools. The ambiance of the residential subdivision also changes by introducing porosities in generally closed spaces. This part of the residential subdivision is closer to the model of garden city ${ }^{4}$ than the model of sector urban planning ([17]).

\section{Storytelling:}

"There is something important in our lives, for our two households: we have opened our two gardens for a very long time. The gardens are...more than adjoining. They are open and we have lots of things in common: the mower, the tools, and the swimming pool!"

\footnotetext{
${ }^{4} \mathrm{~A}$ utopian model which has strongly influenced the creation of residential subdivisions.
} 


\subsubsection{Sharing private basement in Lanaken}

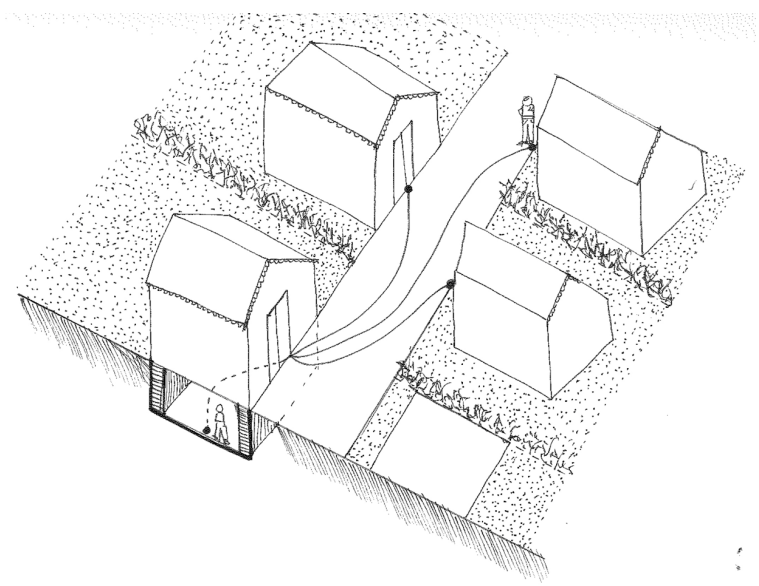

Fig. 6. Sharing private basement in Lanaken @ Safa Ben Kheder

Action: After a change in the family situation, a resident started living alone in a large house. As a result of the change of the household size, the inhabitant was left with a lot of underused space in the house, especially the basement. The resident offered to share the basement with larger families in the neighbourhood in need of extra space to temporarily store things. This action showed the capacity of the inhabitant to modify the very strict plot-by-plot development of the neighbourhood that favour private life over a more collective dimension.

Interaction: As a result of this transformation, some families in the neighbourhood are using a private space for a common purpose. This way, the ambiance of the neighbourhood also changes and introduces the possibility for collective use not only in public spaces but also in private ones.

Storytelling: "Under the house there is a large basement. It is really a lot of space. This space is now a storage for people, for my brother but also for other neighbours who need it. Somebody for instance bought a couch and needed space where to store the old one, so I told them: no problem, you can put it here. And if someone needs space they can use mine."

\subsubsection{Conclusion}

As the comparison shows, porous limits grow from private initiatives and negotiations to transform private spaces to make a better use of them, as shown in the examples, by overcoming the underuse of space or by sharing facilities. They entail a reconfiguration of the space (e.g. elimination of the fences) and/or a rearrangement of its rules (who can use the private space, how, for how long etc.). As these intermediate lived spaces happen in inhabitants' private property, they are facilitated both by social relations as by spatial proximity (e.g. close neighbours) and necessary involve the building of trust between actors. These spaces are subjected to a constant negotiation between people. Therefore, they are temporary and last as long as inhabitants agree. These intermediate lived spaces highlight the 
opportunities to develop retrofitting strategies that are based on the capacities of inhabitants to negotiate and deviate from dwelling models.

\subsection{Transition spaces}

Transition spaces are public spaces that are appropriated over time by collective uses. These spaces are transformed and adapted by the inhabitants in order to facilitate their mobility.

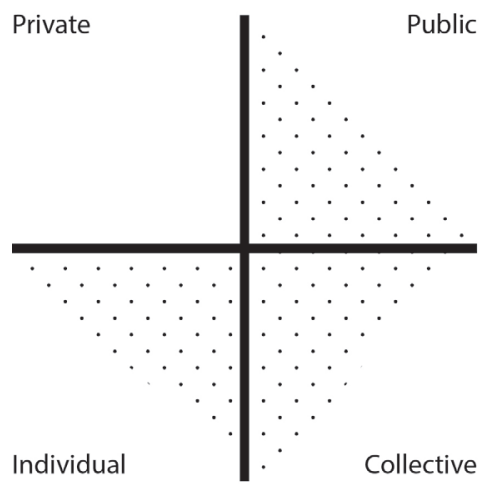

Fig. 7. Intermediate lived spaces analysis model: transition spaces ๑ Marion Serre and Teresa Palmieri

\subsubsection{Collective paths for alternative mobility in Lanaken}

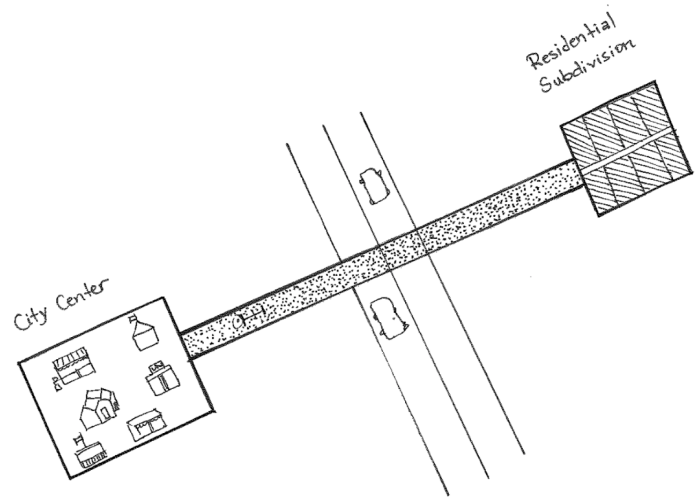

Fig. 8. Collective paths for alternative mobility in Lanaken $\odot$ Safa Ben Kheder

Action: Shortly after the development of the residential subdivision, a large regional double lane road was set up near the neighborhood. To restore the fast connection to the center on foot and by bike, a number of inhabitants reclaimed a part of a residual space in the neighbourhood to build their own shortcut. In this way, they demonstrated their collective capacities to organise collectively to react to macro-scale changes locally and to transform their environment according to their needs at the micro-scale.

Interaction: The shortcut creates interactions on different levels. It creates a new interaction between residents and residual public spaces, which acquire new meanings and functions as 
a result of the collective action of the inhabitants. For example, they become spaces for inhabitants' collective projects and spaces which connect instead of separating. Furthermore, the action triggers a different interaction between the residential subdivision and other close areas (e.g., other neighbourhoods, the town center, etc.). Due to the implementation of the shortcut they become reachable by foot and by bike. Finally, the collective creation of the slow road creates a possible different ambiance for the residential subdivision, not only a caroriented area, but one where other mobility systems are possible.

\section{Storytelling:}

"From this part of the neighbourhood it was not possible to quickly go to the center by bike. People made their own road. Although it is not supported by the municipality, people use it anyway. There should be a better connection between the neighbourhood and the center of the town and facilities, for instance by improving the bike mobility".

\subsubsection{Collective stairs to improve pedestrian mobility in Aix-en-Provence}

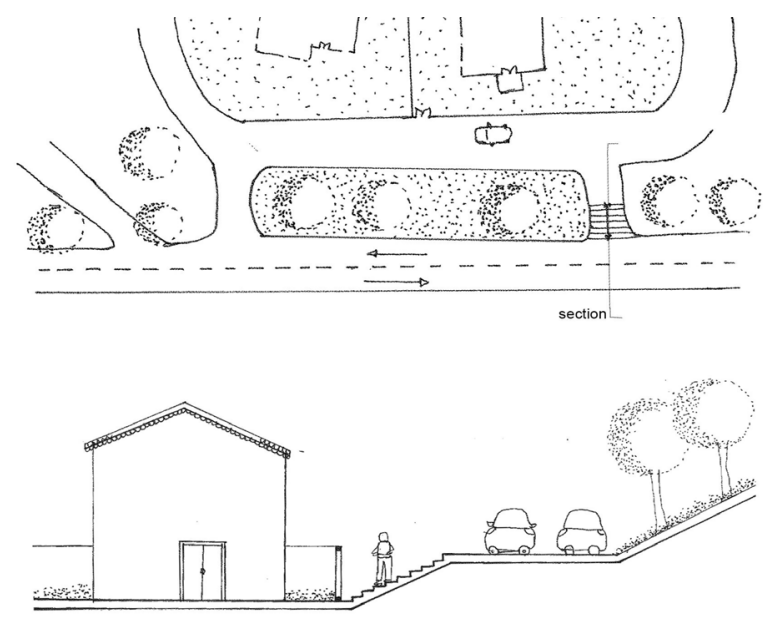

Fig. 9. Collective stairs to improve pedestrian mobility in Aix-en-Provence $\odot$ Safa Ben Kheder

Action: As in many residential subdivisions, public spaces have been conceived for cars. Sidewalks have not been planned and this increases the car-dependency of the inhabitants. Starting from this, the inhabitants of the residential subdivision decided twenty years ago to build these collective stairs.

Interaction: Today, the stairs still work. They are used by all inhabitants: to go shopping in the neighbourhood, for a daily walk or for jogging. Although the stairs have improved pedestrian mobility, residents still face a major problem: there is no sidewalk to get from the stairs to the other neighbourhood.

Storytelling: "If we wanted to go to the other neighbourhood before the stairs, we had to go around to go up and down to the shops. So, we created this staircase to make it easier for us." 


\subsubsection{Conclusion}

Residential subdivisions are most commonly characterised by car-dependency and lack of diversified mobility possibilities. This contributes to the unsustainability of these suburban neighbourhoods, not only from an economic and ecological point of view (e.g. high cost of infrastructures, high-energy demand, pollution, etc.), but also from a societal perspective. For example the increasing ageing residents cannot always rely on cars to move to perform their daily activities. The cases show the capacities of residents to act collectively to diversify the mobility system. They reclaim part of the car-oriented public space and residual public spaces to build slow roads, developing alternative mobility systems that facilitate residents to reach close facilities by bike or on foot. Hence, investigating 'transition spaces' in residential subdivisions can contribute to unveil possibilities for retrofitting strategies that consider slow roads as integral part of a more diversified and less car-oriented mobility system, contributing to transform them into more sustainable urban environments.

\subsection{Street interactions}

We define street interactions as private spaces that are directly in relation with the street and that change the function of the private space (by the opening of a shop for instance) or the atmosphere of the public space (defensible space or open space).

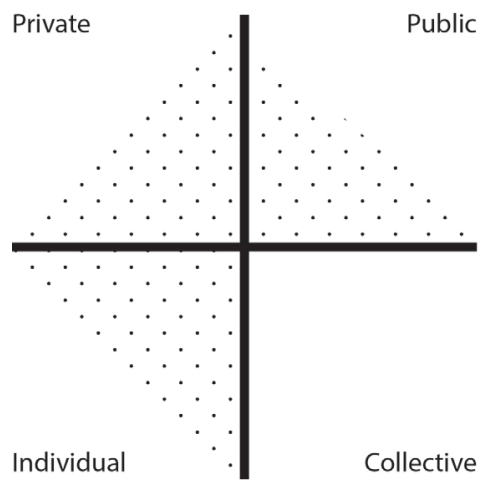

Fig. 10. Intermediate lived spaces analysis model: street interactions ๑ Marion Serre and Teresa Palmieri

\subsubsection{Neighbourhood pop-up shop in a private garage in Lanaken}

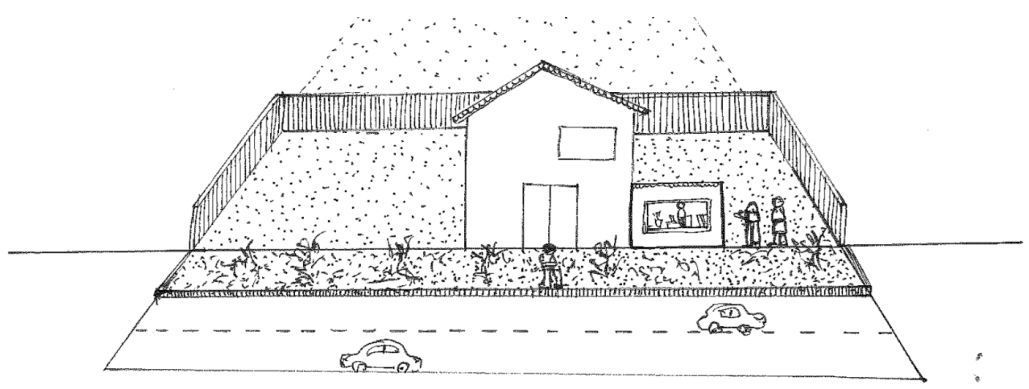

Fig. 11. Neighbourhood pop-up shop in a private garage in Lanaken $\Subset$ Safa Ben Kheder 
Action: One of the inhabitants had transformed his garage into a small neighbourhood bakery open to the public, selling bread and other small goods.

Interaction: This transformation temporarily created a new ambiance for the residential subdivision as a more diversified environment, where functions, other than the residential one, were possible.

Storytelling: "The bakery only lasted one year because for the municipality, these activities are not allowed. It was in a resident's garage and it was great because if I wanted some bread or a drink I didn't have to go to the center, but for some inhabitants the bakery was creating too much traffic."

\subsubsection{Open entrance gates in Aix-en-Provence}

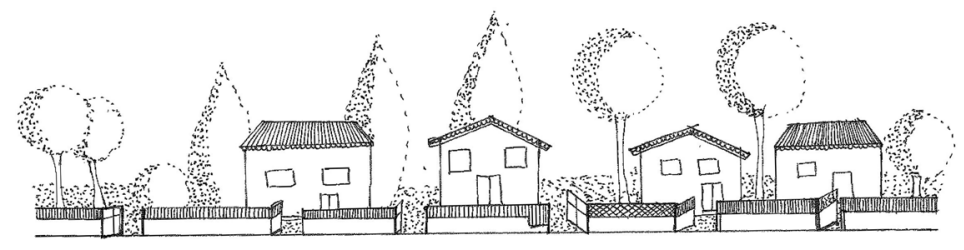

Fig. 12. Open entrance gates in Aix-en-Provence (c) Safa Ben Kheder

Action: In this residential subdivision, many people leave their entrance gates open, because it facilitates their mobility in it. Here, they feel safe and trust their neighbours.

Interaction: This spatial practice creates a special atmosphere less defined by closure and withdrawal than in other residential subdivisions.

Storytelling: "I usually leave my entrance gate open. I have noticed that those who do not do so are more likely to park in front of their homes and not in their own garden. And cars in public space are a problem, both aesthetic and practical for the pedestrians."

\subsubsection{Conclusion}

Residential subdivisions are most often characterised by the clear separation between private and public spaces and by mono-functionality, and, besides a few exceptions, residential subdivisions are made of single-family detached houses that cannot host shops or other facilities. This contributes to residential subdivisions being closed environments. The examples have shown the capabilities of residents to overcome the clear separation between private and public spaces in residential subdivisions by intervening in their private spaces to modify their interaction with the street. By so doing, they create new and more open atmospheres for these environments that may lead also to new functions, such as in the example of the pop-up shop in Lanaken. If on one side residential subdivisions are today often criticised for their mono-functionality, on the other side residents are often reluctant to 
discuss the reconfiguration of the separation between private and public spaces as perceived to disrupt the quiet and private lifestyle that is most common and appreciated in these residential areas. By relying on people's existing capabilities, street interactions of residential subdivisions can open the dialogue toward retrofitting strategies able to transform residential subdivisions into more open environments.

\section{Conclusion}

A proper investigation of intermediate lived spaces not only from the perspective of their spatial and physical configuration but by looking also at how they are conceived, produced, agreed upon and maintained, can enable a deeper understanding of residential subdivisions in their complexity against too simplistic and stereotypical definitions of residential subdivisions as homogeneous environments characterised by individualism. Intermediate lived spaces recognize inhabitants as key actors in processes of retrofitting who themselves constantly reconfigure and improve their neighbourhoods to make it more sustainable for themselves. Inhabitants are thus co-producers of their dwelling spaces that, through their capacities, might transform the ambiances of residential subdivisions. Intermediate lived spaces can become spaces for collective learning about and in urban environments especially because, as hybrid spaces, between private and public, individual and collective spaces, force us to reconsider the binary modes through which space is often perceived, described and designed. In this perspective, intermediate lived spaces invite thinking differently the forms, the ambiances and the meanings of spatiality and interrogate the roles of actors (i.e. inhabitants, local authorities, and spatial practitioners) in retrofitting processes.

The paper has presented a comparison between two case studies, one residential subdivision in France and one in Belgium. The analysis model (Figure 1) has been advanced as a tool to facilitate the comparison of contextual spaces and spatial practices by focusing on the interaction between private and public spaces and individual and collective uses that they present. The model therefore facilitates the emergence of different types of intermediate lived spaces. In this study, we describe three types of intermediate lived spaces we found, namely, porous limits, transition spaces and street interaction. By providing different interactions between private and public spaces and individual and collective uses, they reveal inhabitants capacities of reflecting and acting upon their built up environment and renegotiate spatial relations individually and collectively to improve their neighbourhood according to their needs and values. For instance, the porous limits analysed show the capacity of people to renegotiate private spaces by introducing collective uses and confronting in this way several challenges of residential subdivisions such as space underuse or the high resources waste by facilitating sharing practices. Further, the transition spaces described show the capacity of people to act collectively to re-appropriate the public space for diversify it for instance to develop alternative mobility systems. Finally, street interaction shows the capacities of people to question individualism and mono-functionality of residential subdivisions to develop more diversified, connected and open environments.

As shown in the case studies, participatory forms of urban planning and design can use the provided analysis model not only for having a deeper understanding of residential subdivisions and make more informed and situated retrofitting proposals, but, especially, for revealing the existing capacities of people to transform the spaces of residential subdivisions and renegotiate their purposes (i.e. private, public) and uses (i.e. individual and collective). We therefore propose intermediate lived spaces as possible entry points in processes of participatory urban planning and future-making to help to recognise citizens as full 
participants in the development of urban environments and enhance their engagement in transformation processes such as the retrofitting of residential subdivisions.

\section{References}

1. P. Newman, J.R. Kenworthy, Sustainability and Cities. Overcoming Automobile Dependence, Washington: Island Press (1999)

2. D. Pinson, Le pavillon n'est pas la maison, in SociologieS, Toulouse: Association internationale des sociologues de langue française (2017)

3. A. Touati, J. Crozy, La densification résidentielle au service du renouvellement urbain: filières, stratégies et outil. Paris: La documentation française (2015)

4. White paper for spatial policy plan Flanders, 2016

5. P. Frileux, Le bocage pavillonnaire, une ethnologie de la haie. Grane: Créaphis (2013)

6. R. Dodier, Habiter les espaces périurbains. Rennes: PU (2012)

7. A. Lambert, Tous propriétaires! L'envers du décor pavillonnaire, Paris: Le Seuil (2015)

8. F. Bonnet, Aménager les territoires périurbains et ruraux. Rapport remis au ministère du Logement, de l'Egalité des territoires et de la Ruralité (2016)

9. C. Moley, Les abords du chez-soi. Paris: La Vilette (2006)

10. A. Flamand, L'invention des espaces intermédiaires. Thèse: Paris Est (2008)

11. E. Soja, Thirdspace: Journey to Los Angeles and Other Real-and-Imagined Places, Oxford: Blackwell (1996)

12. L. Roulleau-Berger, La ville intervalle. Jeunes entre centre et banlieue. Paris: ed. Meridiens Klincksieck (1991)

13. S. Tonnelat, Interstices urbains. Entre contrôles et mobilités, quatre espaces résiduels de l'aménagement. Thèse: Université Paris XII et City University of New York (2003)

14. S. Stavrides, Common Space: The City as Commons. London: Wed Books (2016)

15. P. Ehn, E. M. Nilsson, R. Topgaard, Making Futures. The MIT Press, pp.1-13 (2014)

16. S. Pink, Making Homes, UK: Bloomsbury Publishing (2017)

17. D. Mangin, La ville franchisée, Paris: La Vilette (2004)

18. M. Elbakidze, L. Dawson, K. Andersson, R. Axelsson, P. Angelstam, I. Stjerniquist, S. Teitelbaum, P. Schlyer, C. Thellbro, Is spatial planning a collaborative learning process? A case study from a rural-urban gradient in Sweden. Land Use Policy, 48, 270-285 (2015) 